\title{
Seed Production and Seedling Establishment of Parah Trees (Elateriospermum tapos, Euphorbiaceae) in Khao Nan National Park, Thailand
}

\author{
Anun CHAROENSUK, Mullica JAROENSUTASINEE" and \\ Krisanadej JAROENSUTASINEE
}

\author{
Centre of Excellence for Ecoinformatics, School of Science, Walailak University, \\ Nakhon Si Thammarat 80161, Thailand
}

('Corresponding author's e-mail: mullica.jn@gmail.com)

Received: 12 May 2017, Revised: 19 July 2017, Accepted: 18 August 2017

\begin{abstract}
Parah (Elateriospermum tapos Blume) is a native species of southern Thailand, and is a dominant tree in Khao Nan National Park. There have been few studies of Parah seeds or of seedling establishment. Biotic and abiotic environmental factors interact with seeds and may affect the future of tree populations. This is the first study to determine the factors affecting seeds and seedlings of Parah trees in Khao Nan National Park, Thailand, during 2014 - 2016. We tested 3 factors: (1) parental tree diameter at breast height (DBH), (2) altitude, and (3) distance from the main road. We studied seeds collected from trees, seeds harvested by humans, seed predation, seeds left on the forest floor, and rotten seeds. We measured seed weight, seed size, seedling height, and seedling root collar diameter (RCD). Our results showed that the number of seeds and seedlings per tree, seed weight, seed size, seed harvesting, seed predation, seeds left on the forest floor, rotten seeds, and seedling height varied between the years of study. There was no difference in seeds harvested by humans from 2014 - 2016. The number of seeds per tree and seeds harvested by humans were positively associated with parental tree DBH in 2015 and 2016. The number of seeds left on the forest floor was positively associated with parental tree $\mathrm{DBH}$, and distance from the main road, but was negatively associated with altitude, in 2015, and there was no association in 2016 . The number of seeds predated by frugivores was positively associated with altitude in 2016 . The number of seedlings per tree was positively associated with distance from the main road. Seedling height was positively associated with distance from the main road, and negatively associated with tree DBH in 2015 and altitude in both years. We found significant results which led to the conclusion that seed production and seeds harvested by humans were positively associated with parental tree size.
\end{abstract}

Keywords: Khao Nan National Park, Parah, seeds harvested by humans, seed predation, seed production

\section{Introduction}

Understanding factors that affect seed production is important to better characterize the long-term success of tree populations [1]. Seed production can be influenced by resource availability, pollination failure, predation of flowers/fruits/leaves, climatic conditions, and age and size of the plant and its genetic constitution [2-5]. Both abiotic and biotic environmental factors interact with seeds, and these interactions may affect the future of tree populations [6]. Seed production varies among populations due to variable numbers of fruiting trees and seeds yielded per reproductive tree [4,7] and their adaptation with their microhabitats [8]. The highest fruit yields and the largest fruits are found in populations with better climatic conditions and which are protected from herbivorous animals [9,10].

The seedling stage is one of the most critical steps in the reproductive cycle, as this stage can lead to complete regeneration failure in some years, independent of flower and seed crops [11]. Seed germination 
http://wjst.wu.ac.th

and seedling emergence may also be directly affected by microclimatic conditions and indirectly by preand post-dispersal losses of seeds that reduce the number of seeds available for germination [6,12-16]. Some predated seeds may survive and germinate, and survival rates depend on seed size, frugivore types, and level of embryo damage [17-19]. For example, large seeds attacked by insect larvae may have minimal injury to the embryo, which may not prevent germination [18]. In fact, seed germination may be enhanced by pre-dispersal seed predation, because the orifice in the seed produced by the predator may increase embryo access to soil humidity [19-21]. A significant factor of seedling establishment is the interaction between seed predation and seed dispersal $[8,22]$. Seed dispersal losses can be categorized into pre-dispersal losses (e.g., wind and insect predation on flowers and developing fruits) and post-dispersal losses (e.g., stratification during winter, the impact of microclimates, and seeds predated by rodents) [11].

Seeds of tropical tree species vary widely in their size and morphology and are dispersed by a broad array of dispersal agents $[23,24]$. The interaction of local dispersal agents with plant attributes can influence seed dispersal patterns, such as through variation in their movement and in their fruit handling patterns. As a result, these seed dispersal patterns may influence seed viability and spatial patterns of seed deposition [25-27]. Variation in fruit and seed characteristics may affect seed dispersal patterns. Among wind-dispersed species, seed dispersal depends on the aerodynamic properties of diaspores (seeds plus wings or other dispersal appendages), such as their terminal velocities, as well as upon tree height $[28,29]$. Among animal-dispersed species, seed dispersal depends on seed sizes and the ability to attract different dispersal groups through the quantity, quality, and chemical composition of the pulp [25,30-32].

Fruit production, seed dispersal, germination, and seedling establishment are critical life phases in plants [6]. Seed size and number vary greatly both within and among plant individuals, populations, or species $[33,34]$. Seed production is often highly variable from year to year, and individuals of a species are highly synchronized over space and time [35]. For some tree species, this synchronization may encompass large geographic areas [36,37].

Parah (Elateriospermum tapos, Euphorbiaceae) is a canopy tree species whose seeds are a food for local people and wildlife [38,39]. Seed harvesting by humans and seed predation by seed predators can affect seedling establishment. Additionally, parental tree size, altitude, and distance from the main road may affect seed production and seedling establishment, because humans may disturb the forest with differing levels of violence, based on the distance. In this study, we are interested in seed production and seedling establishment of Parah trees. Two predictions were tested. First, larger trees would produce more seeds and seedlings, have larger seed sizes, have larger seedling root collar diameters (RCD), be harvested more by local people, be predated more by frugivores, and leave more on the forest floor than smaller trees. Larger trees would produce more fruits, because they have larger crowns, to capture more sunlight for fruit production, and larger root biomasses, to find water in deeper soil. Larger trees with a lot of seeds would have higher rates of seeds harvested by humans, have more predation by frugivores, and leave more seeds on the forest floor. Second, at higher altitudes and at greater distances from the main road, seeds should be larger, be harvested less by local people, have more left on the forest floor when rotten, and be predated more by frugivores, due to less human disturbance, and there should be more seedlings established on the forest floor. The findings of this study should help us gain a better understanding of the influences of human disturbance on the natural regeneration of the dominant tree species in the southern Thailand tropical rain forest.

\section{Materials and methods}

\section{Parah biology}

Parah (E. tapos) is the only species of the monotypic genus native to peninsular Malaysia, Thailand, Borneo, and Sumatra. Parah trees are found in Jengka national forest in Malaysia [40], Belalong forest in Brunei [41], and Khao Nan National Park in Thailand [38,42]. Parah trees grow in highly dense clusters in some areas in Khao Nan National Park. They grow in the hilly primary (mixed dipterocarp) and secondary forest, in soil which is usually deep and yellow-colored and mainly composed of clay, clayloam, sandy clay, and loam, or sometimes sandstone [43]. This species is abundant in very friable, relatively nutrient-rich soil with a lower water content in dry periods [44]. 


\section{Study area}

This study was conducted in the Parah forest $\left(8^{\circ} 22^{\prime}-8^{\circ} 45^{\prime} \mathrm{N}\right.$ and $\left.99^{\circ} 37^{\prime}-99^{\circ} 51^{\prime} \mathrm{E}\right)$, at an altitude of 166 - 402 m above sea level, located within Khao Nan National Park, southern Thailand (Figure 1a, 1b). Khao Nan National Park is a part of the Nakhon Si Thammarat mountain range, and covers an area of $410 \mathrm{~km}^{2}$. The study site was located in the largest Parah cluster of this national park, in Ban Tub Namtao (Figure 1b). This Parah cluster covers an area of $4.1 \mathrm{~km}^{2}$; it is $3.6 \mathrm{~km}$ long and $0.8-1.7 \mathrm{~km}$ wide. The Parah cluster is parallel to a $10 \mathrm{~m}$ wide dirt road connecting the villages of Ban Tub Namtao and Ban Paklong (Figure 1b). Normally, eight main trails (Figure 1b) are used by local people to harvest Parah seeds from Khao Nan National Park.
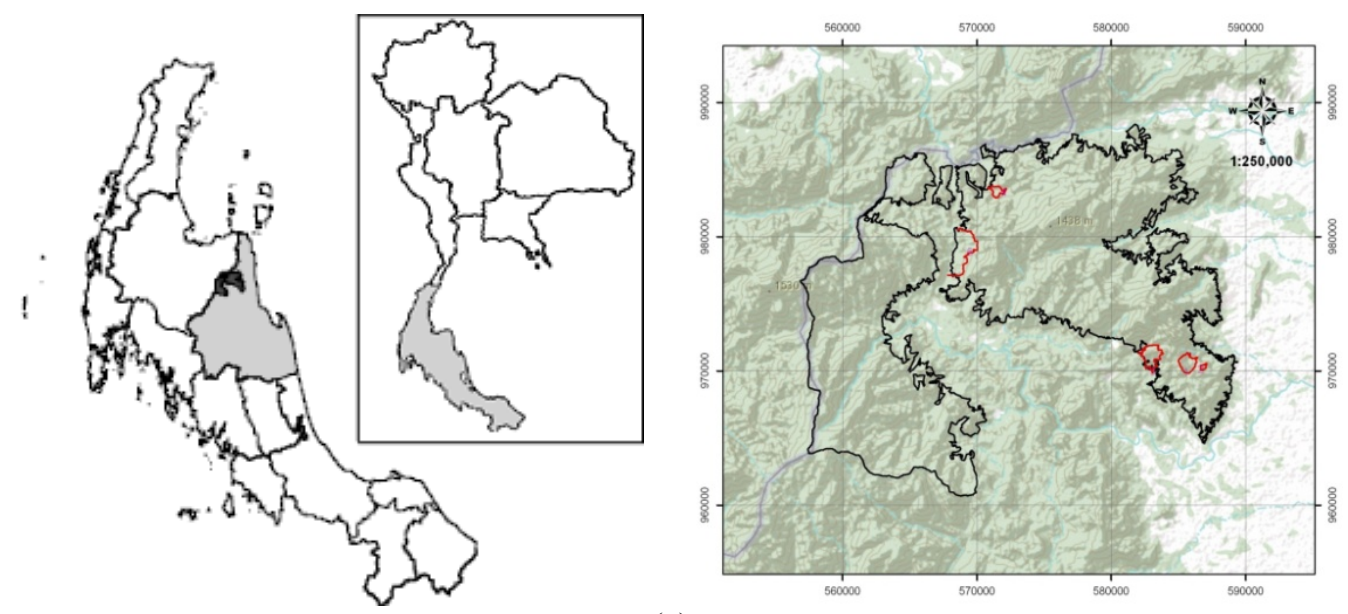

(a)

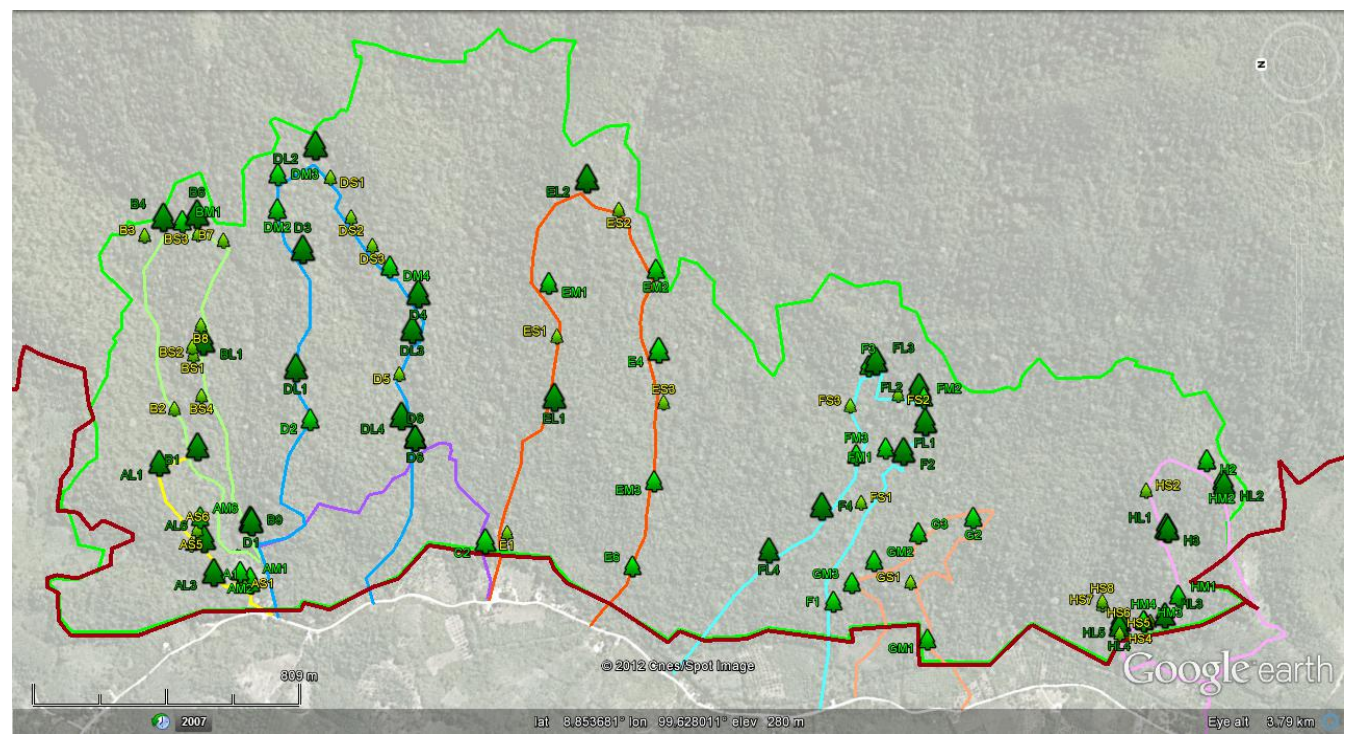

(b)

Figure 1 Map of study sites in southern Thailand. (a) Southern Thailand map, Khao Nan National Park boundary and locations of 5 Parah clusters. Black and red lines represent national park boundary and 5 Parah clusters; (b) the Parah cluster in Ban Tubnamtao (green line). Red, white, and other colour lines represent national park boundary, dirt road, and 8 trails, respectively. Small, medium, and large green trees represent Parah trees with DBH of 21 - 40, $41-60$ and $61-80 \mathrm{~cm}$, respectively. 
http://wjst.wu.ac.th

\section{Data collection}

We randomly selected 36 and 90 fruiting Parah trees from June - July 2014 and 2015, respectively, and measured their DBH (ranging from $20-80 \mathrm{~cm}$ ) on 8 main trails (Figure 1b). From 90 fruiting trees in 2015 , there were only 58 trees fruiting in 2016. Therefore, only 58 fruiting trees were used in this study for the year 2016. Data of Parah seeds and seedlings, including the number of seeds per tree, seed weight, seed width, seed length, seed harvesting by humans, seed predation by seed predators, seeds left on the forest floor, rotten seeds, and the number of seedlings/tree, their root collar diameter (RCD), and height, were collected for 3 years, from 2014 - 2016. We randomly selected 20 seeds per fruiting tree to measure seed weight, seed width, and seed length. Seeds were weighed using a digital balance. Seed width, seed length, and seedling RCD were measured by using a digital Vernier calliper. Seedling height was measured by using a metal tape measure. Ten branches per tree were randomly selected and all the fruits per branch were counted [3,45]; aborted seeds were not counted. Seeds were counted just before maturation in August during 2014 - 2016. The seed production per tree was estimated as follows: total seed production $=$ total number of branches per tree $\times$ average number of fruits per branch $\times 3$ seeds per fruit.

Local people start seed harvesting after seeds begin to fall; they walk on the trails to the locations of the Parah fruiting trees, collect the seeds that fall on the forest floor, and put them in their bags. As it was not possible to count the exact number of seeds harvested by people, we counted (1) the number of seeds left on the forest floor within a $5 \mathrm{~m}$ radius around the selected tree, (2) the number of seeds consumed by frugivores, and (3) the number of rotten seeds. Seeds that were consumed by frugivores were identified as the remains of gnawed off cracked seeds with incisor marks, since rodents are the main Parah seed frugivores. The number of seeds consumed by frugivores would help us to understand seed predation by predators, which causes severe losses in seed crops. Finally, we subtracted all of these values from the total seed production. Therefore, the formula is: number of harvested seeds $=$ total number of seeds per tree - (total number of seeds left + total number of predated seeds + total number of rotten seeds).

We counted the total number of seedlings per parental tree within a $5 \mathrm{~m}$ radius around the selected tree, and randomly selected 10 seedlings to measure their RCD and height in December $2014-2016$. Seedling RCD, height, and numbers were investigated 3 times in a year.

Parametric statistics were used when underlying assumptions were met; otherwise, non-parametric tests were used. One-way ANOVA tests with post hoc Bonferroni adjustments were used to test for differences in the variables. Pearson correlations were used to assess associations between (1) $\mathrm{DBH} / \mathrm{altitude/distance}$ from the main road and the number of seeds/number of harvested seeds/number of predated seeds/number of seeds left on the forest floor/number of rotten seeds and (2) DBH/altitude and the number of seedlings, seedling RCD, and height. All significance tests were 2 tailed.

\section{Results and discussion}

\section{Seed production, seed size and seed fate}

The number of seeds, seed size, and the number of harvested seeds, seeds left on the forest floor, predated seeds, and rotten seeds varied between years (the number of seeds: $F_{2,213}=6.473, P<0.01$; seed width: $F_{2,3617}=317.577, P<0.001$; seed length: $F_{2,3617}=4.509, P<0.05$; seed weight: $F_{2,3617}=29.936$, $P<0.001$; harvested seeds: $F_{2,213}=2.348, n s$; seeds left on the forest floor: $F_{2,213}=34.780, P<0.001$; predated seeds: $F_{2,213}=19.248, P<0.001$; rotten seeds: $F_{2,213}=7.987, P<0.001$, Table 1). 
Table 1 Parah seed production, seed sizes, seed fates and seedling establishment in southern Thailand during the years $2014-2016, *=P<0.05, * *=P<0.01$. Different lower case letters indicate significant differences between years, $P<0.05$.

\begin{tabular}{lcccl}
\hline \multirow{2}{*}{\multicolumn{1}{c}{ Parah seeds and seedlings }} & \multicolumn{3}{c}{ Year (mean \pm SD) } & \multirow{2}{*}{ ANOVA tests } \\
\cline { 2 - 4 } & $\mathbf{2 0 1 4}$ & $\mathbf{2 0 1 5}$ & $\mathbf{2 0 1 6}$ & \\
\hline Seed production (seeds/tree) & $178.92 \pm 251.06^{\mathrm{a}}$ & $112.70 \pm 127.88^{\mathrm{ab}}$ & $75.07 \pm 100.58^{\mathrm{b}}$ & $F_{2,213^{3}}=6.473^{* *}$ \\
Seed weight (g) & $5.00 \pm 1.80^{\mathrm{a}}$ & $4.63 \pm 1.25^{\mathrm{b}}$ & $4.60 \pm 1.12^{\mathrm{b}}$ & $F_{2,3617}=29.936^{* *}$ \\
Seed width (cm) & $1.93 \pm 0.17^{\mathrm{a}}$ & $1.90 \pm 0.14^{\mathrm{b}}$ & $1.87 \pm 0.15^{\mathrm{c}}$ & $F_{2,3617}=317.577^{* *}$ \\
Seed length (cm) & $3.16 \pm 1.14^{\mathrm{a}}$ & $3.55 \pm 0.92^{\mathrm{b}}$ & $3.52 \pm 0.28^{\mathrm{b}}$ & $F_{2,3617}=4.509^{*}$ \\
Seeds harvested by humans (seeds/tree) & $111.72 \pm 208.40$ & $79.68 \pm 122.30$ & $56.93 \pm 92.98$ & $F_{2,213}=2.348$ \\
Seeds predated by frugivores (seeds/tree) & $0.33 \pm 1.29^{\mathrm{a}}$ & $0.34 \pm 0.84^{\mathrm{a}}$ & $3.77 \pm 6.08^{\mathrm{b}}$ & $F_{2,213}=19.248^{* *}$ \\
Seeds left on the forest floor (seeds/tree) & $67.19 \pm 69.02^{\mathrm{a}}$ & $32.68 \pm 19.44^{\mathrm{b}}$ & $14.37 \pm 14.08^{\mathrm{c}}$ & $F_{2,213}=34.780^{* *}$ \\
Rotten seeds (seeds/tree) & - & $0.36 \pm 0.90^{\mathrm{a}}$ & $0.73 \pm 1.22^{\mathrm{b}}$ & $F_{2,213}=7.987^{* *}$ \\
Numbers of seedlings/tree & $68.89 \pm 48.97^{\mathrm{a}}$ & $32.32 \pm 19.31^{\mathrm{a}}$ & $13.63 \pm 13.81^{\mathrm{b}}$ & $F_{2,213}=35.962^{* *}$ \\
Seedling establishment $(\%)$ & $41.40 \pm 31.52^{\mathrm{ab}}$ & $49.63 \pm 28.08^{\mathrm{a}}$ & $31.00 \pm 32.49^{\mathrm{b}}$ & $F_{2,213}=8.383^{* *}$ \\
\hline
\end{tabular}

During the 3 years of observation of Parah trees, the total number of seeds per tree, seed sizes (i.e., seed width, seed length, seed weight), and recruitments decreased from 2014 to 2016. Our results were similar to Aniszewski et al. [46], who showed that, during a 10 year observation period, the total number of Washington lupin (Lupinus polyphyllus Lindl.) seeds per plant decreased, the proportions of each seed type changed, and the average seed weight per plant decreased slightly, from 1990 to 1999. This may have happened due to lower precipitation in the final stages of seed development [47].

While seed production and seeds left on the floor decreased from 2014 to 2016, the number of seeds harvested by humans did not change significantly. On the other hand, the number of predated seeds by frugivores and rotten seeds increased from 2014 to 2016 . The number of predated seeds increased, maybe because of increased numbers of seed predators, and the number of rotten seeds increased, maybe because of increased humidity in the mature seed period. Predated seeds in the tropical rain forest would be damaged and become rotten easily, as there is adequate moisture and plenty of fungi spores everywhere [48].

Factors affecting seeds (Tree DBH, altitude, and distance from the main road)

The number of seeds and seeds harvested by humans were positively associated with the tree DBH in both years (the number of seeds in 2015: $F_{3,86}=4.336, P<0.01 ; y=0.310 x_{d b h}-152.687, R_{\text {adj }}^{2}=0.101$; in 2016: $F_{3,86}=15.000, P<0.001 ; y=0.321 x_{d b h}-224.122, R_{\text {adj }}^{2}=0.321$; the number of seeds harvested in 2015: $F_{3,86}=4.387, P<0.01 ; y=0.275 x_{d b h}-204.143, R_{\text {adj }}^{2}=0.102$; in $2016: F_{3,86}=12.178, P<0.001$; $\left.y=0.334 x_{d b h}-198.439, R_{\text {adj }}^{2}=0.274\right)$.

The number of seeds left on the forest floor was positively associated with the tree DBH and distance from the main road, but negatively associated with altitude in 2015 , and had no association in 2016 (2015: $F_{3,86}=6.221, P<0.005 ; y=0.305 x_{d b h}+0.443 x_{d i s}-0.550 x_{a l t}+51.281, R_{\text {adj }}^{2}=0.150$; in 2016: $\left.F_{3,86}=8.268, P<0.001\right)$.

The number of seeds predated by frugivores was positively associated with altitude in 2016 (in 2015: $F_{3,86}=0.613, n s ;$ in 2016: $\left.F_{3,86}=7.690, P<0.001 ; y=0.560 x_{\text {alt }}-13.397, R_{\text {adj }}^{2}=0.184\right)$.

The number of rotten seeds was positively associated with the distance from the main road and negatively associated with altitude in 2015; on the other hand, the number of rotten seeds was positively associated with altitude in 2016 (in 2015: $F_{3,86}=2.752, P<0.05 ; y=0.491 x_{d i s}-0.364 x_{a l t}+0.841, R_{\text {adj }}^{2}=$ 0.056 ; in 2016: $\left.F_{3,86}=4.346, P<0.01 ; y=0.526 x_{\text {alt }}-2.191, R_{\text {adj }}^{2}=0.101\right)$. 
http://wjst.wu.ac.th

Seed size (width, length, and weight) was positively associated with distance from the main road, but negatively associated with altitude in 2015 (seed width: $F_{3,1796}=6.496, P<0.001 ; y=0.135 x_{\text {dis }}+$ $1.879, R_{\text {adj }}^{2}=0.009$; seed length: $F_{3,1796}=4.033, P<0.001 ; y=0.125 x_{\text {dis }}-0.101 x_{\text {alt }}+3.919, R_{\text {adj }}^{2}=$ 0.005 ; seed weight: $\left.F_{3,1796}=10.951, P<0.001 ; y=0.223 x_{\text {dis }}-0.224 x_{\text {alt }}+5.568, R_{\text {adj }}^{2}=0.016\right)$. In 2016, there were only 58 out of 90 selected trees that were fruiting. Seed size was positively associated with altitude and negatively associated with distance from the main road (seed width: $F_{3,1156}=8.901, P<$ $0.001 ; y=0.167 x_{\text {alt }}-0.211 x_{\text {dis }}+18.569, R_{\text {adj }}^{2}=0.020$; seed length: $F_{3,1156}=20.603, P<0.001 ; y=-$ $0.235 x_{d i s}+36.625, R_{\text {adj }}^{2}=0.048$; seed weight: $F_{3,1156}=7.347, P<0.001 ; y=-0.135 x_{d i s}+5.103, R_{\text {adj }}^{2}=$ $0.016)$.

We found a positive relationship between tree $\mathrm{DBH}$, the number of seeds, the number of harvested seeds, and the number of seeds left on the forest floor. Some previous studies were conducted to ascertain the effects of tree size on seed production [49-53]. Some studies showed no relationship [49], but some showed positive relationships between tree size and the number of fruits or seeds per tree [50,51,53] for Schima khasiana and Lithocarpus dealbatus and, in Quercus griffithii fruiting trees, the seed production was also shown to increase [3]. Large trees produce more fruits, because they have larger crowns; as crown volume increases exponentially with $\mathrm{DBH}$, so does fruit production. The greater fruit production probably reflects a greater capacity to capture sunlight (crown volume) and a correspondingly larger root biomass, which could be expected to reduce the moisture stress experienced during years of low rainfall. These patterns are echoed in the patterns of inter-annual variation in both fruit production and growth [51]. Interestingly, our results indicated that local people tend to harvest seeds from larger trees. These large trees still had more seeds left on the forest floor than smaller trees had. This also showed that larger trees might contribute more to tree recruitment in forests. In addition, our results showed that tree size does not affect seed size (i.e., seed width, seed length, and seed weight). The same result was observed in Euterpe edulis, where DBH did not affect seed size in any population [47]; differences in seed size could possibly be due to the different levels of availability of resources like water, light, nutrients, and pollinators.

At our study site, altitude increases with distance from the main road to the Parah forest. We found that Parah trees located further away from the main road had more rotten seeds left on the forest floor in 2015. The reason behind this might be that it is more difficult for local people to carry bags full of seeds from a high altitude and from greater distances from the main road. In 2016, there might have been more frugivores in the forest farther from the forest edge, so seeds were predated more than the outside. In addition, Parah seeds at higher altitudes were more often rotten than those at lower altitudes, maybe because of the relatively high humidity.

\section{Seedling establishment}

The number of seedlings, seedling height, and RCD varied between years (one-way ANOVA test: number of seedlings: $F_{2,213}=35.962, P<0.001$; seedling height: $F_{2,2697}=112.141, P<0.001$; seedling RCD: $F_{2,2697}=87.335, P<0.001$, Table 1). We observed that the number of seedlings was higher in 2014 than in 2015 and 2016, and probably due to the higher numbers of seeds per tree in 2014 than in 2015 and 2016. Parah flowers appear simultaneously with the new leaves at the beginning of summer (around March) each year, while their fruits start to mature between August and September. The fruits (usually with 3 seeds per fruit) [54] blast and scatter seeds around the tree. After Parah seeds fall on the forest floor, they germinate and grow rapidly within one month, from October - November, with a high germination rate (we observed $98.9 \%$ in 2015 and $94.8 \%$ in 2016, unpublished data). This might be because Parah seed size was larger in 2014 and 2015 than in 2016, supported by previous reports of larger seeds having positive effects on germination [55-64] and seedling growth [55,60,62-65]. The development of early emergence and fast growth of seedlings has been found in other studies to primarily be a result of larger seed size, which produces a larger embryo, therefore providing a greater ability for seedling survival $[66,67]$. 


\section{Factors affecting seedlings}

The number of seedlings was positively associated with distance from the main road and tree DBH, but negatively associated with altitude, in 2015 (the number of seeds in 2015: $F_{3,896}=60.788, P<0.001$; $\left.y=0.421 x_{d i s}+0.295 x_{d b h}-0.535 x_{a l t}+50.621, R_{\text {adj }}^{2}=0.166\right)$. In 2016, the number of seedlings was positively associated with distance from the main road and altitude $\left(F_{3,896}=79.036, P<0.001 ; y=\right.$ $\left.0.258 x_{\text {dis }}+0.222 x_{\text {alt }}-9.868, R_{\text {adj }}^{2}=0.207\right)$.

RCD was positively associated with tree DBH, but negatively associated with altitude, in 2016 and had no association in $2015\left(2015: F_{3,896}=1.518, n s\right.$; in 2016: $F_{3,896}=9.819, P<0.001 ; y=0.082 x_{d b h}-$ $\left.0.133 x_{\text {alt }}+5.947, R_{\text {adj }}^{2}=0.029\right)$.

Seedling height was positively associated with the distance from the main road and negatively associated with tree DBH in 2015 and altitude in both years (in 2015: $F_{3,896}=22.140, P<0.001 ; y=$ $0.312 x_{d i s}-0.068 x_{d b h}-0.434 x_{a l t}+42.605, R_{\text {adj }}^{2}=0.066$; in 2016: $F_{3,896}=14.793, P<0.001 ; y=0.142 x_{d i s}$ $\left.-0.319 x_{\text {alt }}+46.649, R_{\text {adj }}^{2}=0.044\right)$.

Large trees normally produce more seeds than smaller trees of the same age [68]. More seeds generally germinate into more seedlings, so large trees would have more seedlings than smaller trees. In addition, previous studies $[69,70]$ reported that seedling size and growth were related directly to light intensity and seed size: the larger the seed, the larger the seedling. It seems clear that the establishment of seedlings within natural forests depends on the interaction of multiple external factors, both biotic and abiotic, with the physiological and morphological properties of the seedlings [71]. Our results supported this with tree sizes (DBH) being positively associated with the number of seedlings per tree in 2015 and seedling RCD in 2016. The reason that larger mother trees produce larger seedlings could be due to light intensity and sunfleck frequency in the understory of natural forests. Beneath larger Parah trees with an average height of $40 \mathrm{~m}$, there may be higher light intensity and sunfleck frequency than beneath smaller trees. Seedlings growing in the understory of natural forests respond significantly to the frequency and intensity of sunflecks $[72,73]$. The frequency of sunflecks is critical to attain higher carbon balances than those expected under a steady state of photosynthesis.

Seedlings have shown better growth in lower altitude sites than in higher altitude sites [74,75]. Populations originating from lower altitudes exhibited larger growth in seedling height compared to populations from higher altitudes [76]. Our results showed that seedlings at lower altitudes were taller and had a larger RCD than those at higher altitudes. This could be due to 2 possible reasons. First, seedlings in lower-altitude populations were able to benefit from temperature rises and the addition of fertilizer, through accelerated growth, but seedlings in higher-altitude populations experienced no such impact on growth [77]. Second, seeds in lower-altitude populations might fall earlier in the fruiting season and might germinate earlier than in higher-altitude populations.

\section{Conclusions}

In this study, we examined seed production and seedling establishment of Parah trees in a tropical rainforest in southern Thailand. Our results clearly demonstrated that larger Parah trees produce more seeds, left more seeds on the forest floor to germinate, and had more seedlings with larger RCD. In order to have a sustainable population of Parah forests in this area, we need to protect larger Parah trees. Interestingly, local people prefer to collect Parah seeds from larger trees. Even then, there were still more seeds left on the forest floor to germinate. Our results will provide baseline information for further studies on forest conservation and management.

\section{Acknowledgements}

We thank John Barker, John Endler, Fahmida Wazed Tina and 2 anonymous referees for their comments on previous versions of this manuscript. We thank the Walailak University Fund 10/2555, Grant No. WU 58107, and the National Science and Technology Development Agency (NSTDA) (Grant No. P-12-01476), for their financial support, and also thank the Centre of Excellence for Ecoinformatics, NECTEC/Walailak University. Finally, we thank the Khao Nan National Park staff for their invaluable assistance in the field. 
http://wjst.wu.ac.th

\section{References}

[1] EM Nangolo. 2016, Fruiting and Seed Production of Producer and Poor-producer Baobab Trees and on Different Land Use Types in Northern Venda, South Africa. MS Thesis. University of the Witwatersrand, Johannesburg.

[2] AA Winn and PA Werner. Regulation of seed yield within and among populations of Prunella vulgaris. Ecology 1987; 68, 1224-33.

[3] SK Barik, RS Tripathi, HN Pandey and P Rao. Tree regeneration in a subtropical humid forest: Effect of cultural disturbance on seed production, dispersal and germination. J. Appl. Ecol. 1996; 33, 1551-60.

[4] A Ayari and ML Khouja. Ecophysiological variables influencing Aleppo pine seed and cone production: A review. Tree Physiol. 2014; 34, 426-37.

[5] T Wesolowski, P Rowiński and M Maziarz. Interannual variation in tree seed production in a primeval temperate forest: Does masting prevail? Eur. J. Forest Res. 2015; 134, 99-112.

[6] JL Harper. Population Biology of Plants. Academic Press, London, 1977.

[7] EW Schupp. Annual variation in seed fall, postdispersal predation, and recruitment in a neotropical tree. Ecology 1990; 71, 504-15.

[8] HF Howe. Fruit Production and Animal Activity at Two Tropical Trees. In: EG Leigh, AS Rand and DM Windsor (eds.). The Ecology of a Tropical Rain Forest: Seasonal Rhythms and Long-term Changes. Smithsonian Institution Press, Washington DC, 1982, p. 189-200.

[9] M Zunzunegui, F Ain-Lhout, J Jáuregui, MC Díaz Barradas, S Boutaleb, L Alvarez-Cansino and MP Esquivias. Fruit production under different environmental and management conditions of argan, Argania spinosa (L.). J. Arid Environ. 2010; 4, 1138-45.

[10] V Loewe-Muñoz, M Balzarini, A Álvarez, Cl Delard and RM Navarro. Fruit productivity of Stone pine (Pinus pinea L.) along a climatic gradient in Chile. Agr. Forest Meteorol. 2016; 223, 1-14.

[11] GJM Pastur, RS Esteban, F Pulido and MV Lencinas. Variable retention harvesting influences biotic and abiotic drivers of regeneration in Nothofagus pumilio southern Patagonian forests. Forest Ecol. Manag. 2013; 289, 106-14.

[12] DH Janzen. Herbivores and the number of tree species in tropical forests. Am. Nat. 1970; 104, 5018.

[13] A Powell and G Powell. Population dynamics of male euglossine bees in Amazonian forest fragments. Biotropica 1987; 19, 176-9.

[14] M Schelin, M Tigabu, I Eriksson, L Sawadogo and PC Odén. Predispersal seed predation in Acacia macrostachya, its impact on seed viability, and germination response to scarification and dry heat treatments. New Forest 2004; 27, 251-67.

[15] M Shaban. Effect of water and temperature on seed germination and emergence as a seed hydrothermal time model. Int. J. Biomed. Adv. Res. 2013; 1, 1686-91.

[16] C Leroy, F Petitclerc, J Orivel, B Corbara, JF Carrias, A Dejean and R Céréghino. The influence of light, substrate and seed origin on the germination and establishment of an ant-garden bromeliad. Plant Biol. 2017; 19, 70-8.

[17] J Dalling, KE Harms and RJ Aizprúa. Seed damage tolerance and seedling resprouting ability of Prioria copaifera in Panama. Trop. Ecol. 1997; 13, 481-90.

[18] M Vallejo-Marín, CA Domínguez and R Dírzo. Simulated seed predation reveals a variety of germination responses of neotropical rain forest species. Am. J. Bot. 2006, 93, 369-76.

[19] AP Loayza, PR Gachon, P García-Guzmán, DE Carvajal and FA Squeo. Germination, seedling performance, and root production after simulated partial seed predation of a threatened Atacama Desert shrub. Rev. Chil. Hist. Nat. 2015; 88, 10.

[20] PJ Grubb. The maintenance of species-richness in plant communities: The importance of the regeneration niche. Biol. Rev. 1977; 52, 107-45.

[21] CC Baskin and JM Baskin. Seeds: Ecology, Biogeography, and Evolution of Dormancy and Germination. Academic Press, San Diego, 1998. 
http://wjst.wu.ac.th

[22] P Sunyer, E Boixadera, A Muñoz, R Bonal and JM Espelta. The interplay among acorn abundance and rodent behavior drives the spatial pattern of seedling recruitment in mature Mediterranean oak forests. Plos One 2015; 10, e0129844.

[23] HC Muller-Landau and BD Hardesty. Seed Dispersal of Woody Plants in Tropical Forests: Concepts, Examples, and Future Directions. In: D Burslem, M Pinard and S Hartley (eds.). Biotic Interactions in the Tropics: Their Role in the Maintenance of Species Diversity. Cambridge University Press, Cambridge, 2005, p. 267-309.

[24] HF Howe. Making dispersal syndromes and networks useful in tropical conservation and restoration. Glob. Ecol. Conserv. 2016; 6, 152-78.

[25] HF Howe. Scatter and clump-dispersal and seedling demography: Hypothesis and implications. Oecologia 1989; 79, 417-26.

[26] DG Wenny and DJ Levey. Directed seed dispersal by bellbirds in a tropical cloud forest. Proc. Nat. Acad. Sci. 1998, 95, 6204-07.

[27] DA Westcott, J Bentrupperbaumer, MG Bradford and A McKeown. Incorporating patterns of disperser behaviour into models of seed dispersal and its effects on estimated dispersal curves. Oecologia 2005; 146, 57-67.

[28] CK Augspurger. Morphology and dispersal potential of wind dispersed diaspores of neotropical trees. Am. J. Bot. 1986; 73, 353-63.

[29] R Nathan, UN Safriel and I Noy-Meir. Field validation and sensitivity analysis of a mechanistic model for tree seed dispersal by wind. Ecology 2001; 82, 374-88.

[30] PJ Grubb. Seeds and Fruits of Tropical Rainforest Plants: Interpretation of the Range in Seed Size, Degree of Defence and Flesh/Seed Quotients. In: DM Newbery, HHT Prins and ND Brown (eds.). Dynamics of Tropical Communities Blackwell Scientific, Oxford, 1998, p. 1-24.

[31] JJ Tewksbury and GP Nabhan. Seed dispersal: Directed deterrence by capsaicin in chillies. Nature $2001 ;$ 412, 403-4.

[32] J Farias, M Sanchez, MF Abreu and F Pedroni. Seed dispersal and predation of Buchenavia tomentosa Eichler (Combretaceae) in a Cerrado sensu stricto, midwest Brazil. Braz. J. Biol. 2015; 75, 88-96.

[33] CM Herrera. Multiplicity in Unity: Plant Subindividual Variation and Interactions with Animals. University of Chicago Press, Chicago, USA, 2009.

[34] Z Xiao, Z Zhang and CJ Krebs. Seed size and number make contrasting predictions on seed survival and dispersal dynamics: A case study from oil tea Camellia oleifera. Forest Ecol. Manag. 2015; 343, 1-8.

[35] D Kelly and VL Sork. Mast seeding in perennial plants: Why, how, where? Annu. Rev. Ecol. Evol. Syst. 2002; 33, 427-47.

[36] EM Schauber, D Kelly, P Turchin, C Simon, WG Lee, RB Allen, J Payton, PR Wilson, PE Cowan and RE Brockie. Masting by eighteen New Zealand plant species: The role of temperature as a synchronizing cue. Ecology 2002; 83, 1214-25.

[37] A Liebhold, WD Koenig and ON Bjørnstad. Spatial synchrony in population dynamics. Annu. Rev. Ecol. Evol. Syst. 2004; 35, 467-90.

[38] A Charoensuk, M Jaroensutasinee and K Jaroensutasinee. Parah forest clusters at Khao National Park, Thailand. Walailak J. Sci. Tech. 2012; 9, 75-80.

[39] TK Lim. Edible Medicinal and Non-medicinal Plant: Elateriospermum tapos. Springer, Netherlands, 2012, p. 472-5.

[40] N Osada, H Takeda, H Kawaguchi, A Furukawa and M Awang. Estimation of crown characters and leaf biomass from leaf litter in a Malaysian canopy species, Elateriospermum tapos (Euphorbiaceae). Forest Ecol. Manag. 2003; 89, 379-86.

[41] E Cranbrook and DS Edwards. A Tropical Rainforest: The Nature of Biodiversity in Borneo at Belalong, Brunei. The Royal Geographical Society and Sun Tree Publishing, Singapore, 1994, p. 389.

[42] S Chumkiew, W Srisang, K Jaroensutasinee and M Jaroensutasinee. Phenology of the Parah tree (Elateriospermum tapos) using a GAPS Model. Int. J. Math. Phys. Eng. Sci. 2007; 2, 1-5. 
http://wjst.wu.ac.th

[43] HV Sam and PCV Welzen. Revision of Annesijoa, Elateriospermum and the introduced species of Hevea in Malaysia (Euphorbiaceae). Blumea 2004; 49, 425-40.

[44] CC Ho, MC Newbery and ED Poore. Forest composition and inferred dynamics in Jengka Forest Reserve, Malaysia. J. Trop. Ecol. 1987; 3, 25-56.

[45] ML Khan, P Bhuyan, U Shakar and NP Todaria. Seed germination and seedling fitness in Mesua ferrea L. in relation to fruit size and seed number per fruit. Acta Oecol. 1999; 20, 599-606.

[46] T Aniszewski, MH Kupari and AJ Leinonen. Seed number, seed size and seed diversity in Washington lupin (Lupinus polyphyllus Lindl.). Ann. Bot. 2001; 87, 77-82.

[47] PHS Brancalion and RR Rodrigues. Seed size-number trade-off in Euterpe edulis in plant communities of the Atlantic Forest. Sci. Agr. 2014; 71, 1-8.

[48] DH Janzen. Why fruits rots, seeds mold, and meat spoils. Am. Nat. 1997; 111, 691-713.

[49] ED Hardin. Variation in seed weight number per capsule and germination in Populus deltoides trees in southeastern Ohio USA. Am. Midl. Nat. 1984; 112, 29-34.

[50] JC Stromberg, and DT Patten. Seed and cone production by Engelmann spruce in the Pinaleno Mountains, Arizona. J. Ariz. Nev. Acad. Sci. 1993; 27, 97-110.

[51] LK Snook, L Cámara-Cabrales and MJ Kelty. Six years of fruit production by mahogany trees (Swietenia macrophylla King): Patterns of variation and implications for sustainability. Forest Ecol. Manag. 2005; 206, 221-35.

[52] A Burgos, AA Grez and RO Bustamante. Seed production, pre-dispersal seed predation and germination of Nothofagus glauca (Nothofagaceae) in a temperate fragmented forest in Chile. Forest Ecol. Manag. 2008; 255, 1226-33.

[53] MM Mathew, MR Munjuga, HJ Ndanggalasi and NJ Cordeiro. Aspects of the floral and fruit biology of Allanblackia stuhlmannii (Clusiaceae), an endemic Tanzanian tree. J. East Afr. Nat. Hist. 2009; 98, 79-93.

[54] C Ngamriabsakul and H Kommen. The preliminary detection of cyanogenic glycosides in Pra (Elateriospermum tapos Blume) by HPLC. Walailak J. Sci. Tech. 2009; 6, 141-7.

[55] BA Schaal. Reproductive capacity and seed size in Lupinus texensis. Am. J. Bot. 1980; 67, 703-9.

[56] MI Weis. The effects of propagule size on germination and seedling growth in Mirabilis hirsuta. Can. J. Bot. 1980; 60, 1868-74.

[57] JK Zimmerman and IM Weis. Fruit size variation and its effects on germination and seedling growth in Xanthium strumarium. Can. J. Bot. 1983; 61, 2309-15.

[58] RW Dolan. The effect of seed size and maternal source on individual size in a population of Ludwigia leptocarpa (Onagraceae). Am. J. Bot. 1984; 71, 1302-7.

[59] ML Stanton. Seed variation in wild radish: Effect of seed size on components of seedling and adult fitness. Ecology 1984; 65, 1105-12.

[60] DH Morse and J Schmitt. Propagule size, dispersal ability, and seedling performance in Asclepias syrica. Oecologia 1985; 67, 372-9.

[61] AA Winn. Ecological and evolutionary consequences of seed size in Prunella vulgaris. Ecology $1988 ; 69,1537-44$.

[62] RS Tripathi and ML Khan. Effects of seed weight and microsite characteristics on germination and seedling fitness in two species of Quercus in a subtropical wet hill forest. Oikos 1990; 57, 289-96.

[63] ML Vera. Effects of altitude and seed size on germination and seedling survival of heathland plants in north Spain. Plant Ecol. 1997; 133, 101-6.

[64] R Kumar, GS Shamet, NM Alam and C Jana. Influence of growing medium and seed size on germination and seedling growth of Pinus gerardiana Wall. Compost Sci. Util. 2016; 24, 98-104.

[65] R Wulff. Seed size variation in Desmodium paniculatum. II. Effects on seedling growth and physiological performance. J. Ecol. 1986; 74, 99-114.

[66] LD Leverett and CL Jolls. Cryptic seed heteromorphism in Packera tomentosa (Asteraceae): Differences in mass and germination. Plant Species Biol. 2014; 29, 169-80.

[67] F Yang, JM Baskin, CC Baskin, X Yang, D Cao and Z Huang. Effects of germination time on seed morph ratio in a seed-dimorphic species and possible ecological significance. Ann. Bot. 2015; 115, 137-145. 
http://wjst.wu.ac.th

[68] CA Chapman, LJ Chapman, RW Wrangham, K Hunt, D Gebo and L Gardner. Estimators of fruit abundance of tropical trees. Biotropica 1992; 24, 527-31.

[69] C Phonguodume, DK Lee, S Sawathvong, YD Park, WM Ho and EA Combalicer. Effects of light intensities on growth performance, biomass allocation and chlorophyll content of five tropical deciduous seedlings in Lao PDR. J. Environ. Sci. Manag. 2012; 15, 60-7.

[70] CC Pinchot, SL Clark, SE Schlarbaum, AM Saxton, SS Sung and FV Hebard. Effects of temporal dynamics, nut weight and nut size on growth of American chestnut, Chinese chestnut and backcross generations in a commercial nursery. Forests $2015 ; \mathbf{6}, 1537-56$.

[71] E Medina. Seedling establishment and endurance in tropical forests: Ecophysiology of stress during early stages of growth. Oecologia Australis 2009; 4, 23-43.

[72] RL Chazdon and RW Pearcy. Photosynthetic responses to light variation in rainforest species. II. Carboxylation gain and photosynthesis efficiency during lightflecks. Oecologia 1986; 69, 524-31.

[73] RW Pearcy. Photosynthetic utilisation of sunflecks. Aust. J. Plant Physiol. 1988; 15, 223-38.

[74] K Espahbodi, HM Nodoushan, M Tabari, M Akbarinia, SG Jalali and SM Hosseini. Seed source effects on seed emergence, seedling survival and growth on wild service (Sorbus torminalis) seedlings. Int. J. Agr. Biol. 2007; 9, 426-30.

[75] U Yaqoob and IA Nawchoo. Impact of habitat variability and altitude on growth dynamics and reproductive allocation in Ferula jaeschkeana Vatke. J. King Saud Univ. Sci. 2017; 29, 19-27.

[76] C Sáenz-Romero, GE Rehfeldt, JC Soto-Correa, S Aguilar-Aguilar, V Zamarripa-Morales and J López-Upton. Altitudinal genetic variation among Pinus pseudostrobus populations from Michoacán, México. Two location shadehouse test results. Rev. Fitotec. Mex. 2012; 35, 111-21.

[77] FE Wielgolaski, PS Karlsson, S Neuvonen and D Thannheiser. Plant Ecology, Herbivory and Human Impact in Nordic Mountain. Springer, Germany, 2005. 